\title{
O SUJEITO CONTEMPORÂNEO E O TRABALHO: UM OLHAR DISCURSIVO PARA OS EFEITOS DE MEDICALIZAÇÃO
}

\author{
FERNANDA LUZIA LUNKES ${ }^{1}$
}

Instituto de Humanidades, Artes e Ciências - Campus Jorge Amado

Universidade Federal do Sul da Bahia

Rua Itabuna, s/n, Rod Ilhéus-Vitória da Conquista, km 39, BR 415 - 45613-204

Ferradas, Itabuna-BA - Brasil

flunkes@gmail.com

Resumo. Neste estudo, que recorta e aprofunda uma pesquisa mais ampla (LUNKES, 2014), situaremos algumas discursividades sobre trabalho cujo funcionamento fortalece os efeitos de evidência (PÊCHEUX, 2009 [1975]) nas relações de sentidos que o sujeito estabelece com o trabalho e com a necessidade de uso de medicamento. Veremos que o trabalho comparece como um modo pelo qual o sujeito alcança valorização na formação social capitalista. Segundo Orlandi (2007, p. 15), esta formação social de "cultura heroica do sujeito" funciona coercitivamente e torna-o responsável pelo sucesso ou fracasso de seus empreendimentos. Deste modo, além de corroborar para um quadro social de medicalização (BARROS, 2004), há diferentes direções nas produções de sentidos sobre o quadro depressivo.

Palavras-chave: Análise de Discurso; sujeito; trabalho; medicalização; contemporaneidade.

\begin{abstract}
In this study, which cuts and deepens a wider research (LUNKES, 2014), we will situate discursivities about work whose functioning strengthens the effects of evidence (PECCHEUX, 2009 [1975]) in the relations of senses that the subject establishes with work and with the need for medicament use. The work appears as one way in which the subject reaches appreciation in the capitalist social formation. According to Orlandi (2007, p. 15), this social formation of "heroic culture of the subject" works coercively and makes him responsible for the success or failure of his endeavors. That way, in addition to corroborate to a social frame of medicalization (BARROS, 2004), there are different directions in the production of meanings about depressive symptoms.
\end{abstract}

Keywords: Discourse Analysis; subject; work; medicalization; contemporaneity.

\footnotetext{
${ }^{1}$ Doutora em Estudos da Linguagem (UFF). Professora no Instituto de Humanidades, Artes e Ciências, Campus Jorge Amado, da Universidade Federal do Sul da Bahia.
} 


\section{Considerações iniciais}

O presente estudo retoma e aprofunda parte de uma pesquisa mais ampla (LUNKES, 2014), na qual tínhamos como objetivo, à luz da Análise de Discurso, analisar os processos de produção de sentidos sobre depressão no discurso jornalístico de Veja, de 1968 a 2010. Analisamos diferentes materialidades significantes (LAGAZZI, 2009), verbais e imagéticas, nas quais se buscou compreender o imaginário posto em circulação sobre depressão, sobre sujeito deprimido (enquanto posição discursiva construída no discurso jornalístico) e sobre medicamentos (antidepressivos, tranquilizantes e ansiolíticos). Vale ressaltar que o termo 'depressão' comparece em referência ao trabalho de Horwitz \& Wakefield (2010): uma expressão genérica e que abrange "todo tipo de tristeza, seja normal ou patológica" (idem, p. 40), e por ser, também, um termo que comparece regularmente em diferentes materialidades discursivas quando está em jogo a produção de evidências nos sentidos sobre afetos e sintomas.

Ainda situando a pesquisa anterior e mais ampla. Naquele percurso, dedicamonos também a apontar para algumas discursividades, "inscrição dos efeitos da língua na história" (ORLANDI, 2001, p. 20), e suas relações de sentidos com depressão na contemporaneidade à medida que aquelas, em seus processos de formulação e circulação, contribuem para uma produção de sentidos de evidência sobre depressão: a noção de felicidade, o sintoma melancólico e o trabalho.

Sobre as condições de produção, Pêcheux (1997 [1969], p. 78), na formulação teórica da Análise de Discurso, adverte que a análise do funcionamento do discurso não ocorre somente pela análise do fio do discurso: é necessário também colocar tais "fenômenos linguísticos" em relação a outros elementos, apresentados como "protagonistas" e "objeto do discurso". Indursky (2010, p. 69) explica que a denominação 'contexto', aquilo que é exterior ao discurso, possui natureza sócio-histórica. Segundo a autora, "[...] as condições de produção de um texto relacionam este texto a sujeitos históricos, que se identificam com uma formação discursiva, e estão inscritos em lugares sociais, construídos ideologicamente".

Desta maneira, o presente estudo empreende um recorte da pesquisa realizada, situando algumas discursividades que circulam sobre trabalho e alguns dos efeitos de sentidos produzidos. Compreendemos que, em seus modos de formulação e circulação, tais discursividades apontam para um funcionamento que fortalece os efeitos de evidência, próprio do mecanismo ideológico (PÊCHEUX, 2009 [1975]), dos sentidos estabelecidas pelo sujeito em relação ao trabalho e à necessidade de uso de medicamento (antidepressivos, tranquilizantes e ansiolíticos) para além do uso terapêutico, como no tratamento do quadro depressivo ${ }^{2}$, por exemplo.

\footnotetext{
2 O uso de medicamento constitui um "ponto nodal" (PÊCHEUX, 2009 [1975]) nas relações de forças produzidas entre os discursos psiquiátrico e psicanalítico. Nossa tomada de posição, nessas tensões discursivas, não é contrária ao uso de medicamento. Compreendemos, em consonância com Nazar (2003, p.103), que “[...] em situações de risco ou de uma crise emocional grave, uma medicação permite uma estabilização do quadro, no sentido de uma abertura à transferência". Nosso objetivo é situar discursividades que, em seus movimentos de sentidos, fortalecem o efeito de evidência um uso de medicamento e que em grande medida se desloca do uso terapêutico.
} 


\section{Os discursos sobre trabalho e a emergência do sujeito empreendedor}

Para iniciar nosso percurso, situaremos, ainda que brevemente, algumas questões em torno do trabalho no modo de produção capitalista tal como teorizado nos estudos de Marx. Tais recortes permitem compreender alguns movimentos discursivos e que colocam em relevo os modos pelos quais os sentidos sobre trabalho são administrados em uma dada formação social (MARIANI, 1998).

Na obra $O$ Capital, o trabalho, considerado em $O$ manifesto comunista enquanto "condição para o capital" (MARX; ENGELS, 1997 [1848], p. 28), é equivalente à "utilização da força de trabalho" (MARX, 1996 [1867], p. 297). Deste modo, o sujeito, ao ocupar a posição sujeito trabalhador, vende ao empregador sua força de trabalho, definida como "conjunto das faculdades físicas e espirituais que existem na corporalidade, na personalidade viva de um homem e que ele põe em movimento toda vez que produz valores de uso de qualquer espécie" (ibidem, p. 285).

Marx compara a força de trabalho a qualquer mercadoria. Uma vez inserido em um certo campo de atuação, o trabalhador vende sua força de trabalho e, neste movimento, esta é "consumida, ou usada, fazendo-o trabalhar, assim como se consome ou se usa uma máquina fazendo-a funcionar" (ibidem, p. 101). Esta relação de sentidos trabalhador/máquina permite depreender uma produção de efeito de sentido na qual as escolhas do trabalhador são silenciadas em detrimento das demandas do empregador, que estabelece as regras de atuação no espaço de trabalho. A efetividade da venda da força de trabalho só é passível de ser medida quando colocada em prática, quando a produção se faz visível.

Sobre este aspecto, é relevante destacar a observação feita por Marx a respeito da "ativação" da força de trabalho. Para o autor, do trabalhador será demandado "determinado quantum de músculo, nervo, cérebro etc. humanos que precisa ser reposto" (ibidem, p. 288). Articulando o destaque feito por Marx à perspectiva discursiva, podemos afirmar que a materialidade do corpo discursivo (FERREIRA, 2011) é posta em relevo a partir das demandas produzidas sobre o corpo discursivo no espaço do trabalho. Acrescentamos que também será a partir desta materialidade a produção de fortes efeitos de sentidos indesejados no trabalho no modo de produção capitalista: baixo rendimento, preguiça e depressão, entre outros.

No modo de produção capitalista, o trabalho é uma das vias pelas quais o sujeito estabelece processos de identificação e alcança valorização na formação social, produzindo efeitos de singularização. Conforme Orlandi (2007, p. 15), trata-se de uma formação social que coloca em causa uma "cultura heroica do sujeito" e que o torna responsável pelo sucesso ou fracasso de seus empreendimentos e resultados. Tal discursividade funciona coercitivamente à medida que demanda determinadas formulações discursivas do sujeito, que pode ser segregado socialmente caso não seja bem-sucedido nesta empreitada. Segregação que muitas vezes impossibilita o sujeito de apostar na mudança de sua condição social.

O funcionamento discursivo sobre trabalho pode ser situado a partir de Pêcheux (2012 [1979], p. 80). Discutindo as bases políticas da propaganda, o autor coloca duas "formas históricas concorrentes" como modos de produção capitalista: 1) "via 'dita' 
americana" e 2) "via 'dita' prussiana". Dedicaremos nosso olhar, no presente estudo, à primeira via.

A via americana, segundo Pêcheux, consiste em um modo de elaboração discursiva na qual "o produtor independente torna-se ele próprio progressivamente comerciante e capitalista" (PÊCHEUX, 2012 [1979], p. 80). Neste funcionamento capitalista, o sujeito é alçado no discurso como autor de sua própria história, alguém que se faz e refaz por si mesmo. Uma das consequências apontadas por Pêcheux consiste na relação com o passado, que "está apagado ou ausente" (ibidem, p. 81).

Podemos relacionar esta questão apresentada em Pêcheux à afirmação de Orlandi (2001) acerca da relação da forma-sujeito capitalista com a (im)posição de uma vontade do sujeito na linguagem. Uma relação contraditória na qual o sujeito tem a liberdade para tudo dizer e, ao mesmo tempo, é submetido às coerções que o responsabilizam por tudo o que diz. O que é dito pelo sujeito e o modo como diz passam a se inscrever no domínio da vontade e passam a ser consideradas como questões pragmáticas que (en)cerram o sujeito em seu discurso.

Retomando Pêcheux, este autor denomina "gestão da subjetividade" este funcionamento discursivo no qual "o sujeito contribui ativamente para seu assujeitamento através de um sinistro jogo de palavras sobre o termo liberdade" (PÊCHEUX, 2012 [1979], p. 88, itálicos do original). Segundo o autor, o funcionamento discursivo do termo 'liberdade' se produz hegemonicamente no interior das práticas discursivas de mercado, que submetem o sujeito principalmente ao consumo. Pêcheux cita Henry Ford para situar um enlaçamento do sujeito consumidor neste funcionamento: "Nós liberamos ao cliente o carro na cor de sua escolha... com a condição que ele a queira preta" (idem).

Podemos relacionar este exemplo de Pêcheux sobre o funcionamento discursivo de 'liberdade' com a definição de Marx \& Engels (1997 [1848], p. 35). Segundo os autores, no modo de produção capitalista, o termo 'liberdade' refere-se a "mercado livre, venda livre e compra livre". Depreende-se que liberdade tem seus processos de significação fortemente cerceados pelas formas de negociação das mercadorias e pelo consumo dos sujeitos. Um sujeito que consome e que ao fazê-lo atua imaginariamente em uma liberdade de escolha dentre as opções disponíveis, sustentadas pelo imaginário de que contemplam todas as possibilidades.

Ainda neste movimento de sentidos, trazemos o estudo de Mariani e Magalhães (2011) que se dedica, também, a compreender o consumo na contemporaneidade. Para tanto, vale destacar o que colocam as autoras sobre o sujeito contemporâneo: este, além de estar envolvido em um processo de submissão ao Sujeito do capital, possui entre seus traços uma intensa preocupação com suas próprias questões, além de uma busca no consumo. Conforme explicam as autoras, uma subjetividade que se enlaça fortemente à lógica da mercadoria e desliza para uma lógica segundo a qual "Todos querem apenas sobreviver e usufruir sempre, para fazer jus a seu lugar no mundo como representantes maior do ícone da sociedade contemporânea: o consumo" (MARIANI; MAGALHÃES, 2011, p. 135).

De uma perspectiva sociológica, Ehrenberg (2010) estuda as relações construídas na contemporaneidade entre sociedade, medicamentos e depressão. Sua pesquisa aponta 
para uma mudança nos processos de subjetivação: o termo 'performance' funciona discursivamente de modo a mobilizar a imagem de um sujeito que produz a sua história individualmente. Articulando o exposto em Marx acerca das demandas a que o trabalhador terá de atender no trabalho, especificamente no que se refere à materialidade do corpo ("determinado quantum de músculo, nervo, cérebro etc. humanos [...]" (MARX, 1996 [1867], p. 288), compreendemos que, diante da responsabilização do sujeito na forma-sujeito capitalista, a materialidade do corpo discursivo atua de modo fundamental para sustentar ou desconstruir efeitos de sentidos de um sujeito bem-sucedido, produtivo, eficiente.

Pode-se afirmar que nestas práticas discursivas são silenciadas as condições materiais que permitem ao sujeito, no modo de produção capitalista, ascender socialmente. Deste modo, os efeitos construídos produzem uma espécie de fechamento de sentidos, tornando este sujeito o único responsável pelo seu fracasso ou sucesso. Segundo o sociólogo, todo indivíduo é interpelado em um sujeito que se torna o personagem principal de sua própria história. Tal prática discursiva "impulsiona cada um a se singularizar, tornando-se si mesmo" (EHRENBERG, 2010, p. 10).

Estes efeitos de sentidos que o sujeito empreende sobre si, enquanto autor que se lança sozinho à construção de sua própria história, é definida por Ehrenberg (2010) pelo termo 'empreendedor'. Segundo o autor, este termo situa um movimento no discurso capitalista que torna possível a construção do imaginário social de um sujeito que produz sentidos de "modelo de vida heroica" porque "resume um estilo de vida que põe no comando a tomada de riscos numa sociedade que faz da concorrência interindividual uma justa competição" (EHRENBERG, 2010, p. 13).

De acordo com Ehrenberg (2010), esta prática discursiva na qual o sujeito deve se fazer por si mesmo silencia os efeitos de sentidos de concorrência entre " $\mathrm{X}$ " e " $Y$ ", concorrência esta que fundamenta o trabalho assalariado (MARX; ENGELS, 1997 [1848], p. 28), para colocar em evidência a concorrência do sujeito também consigo mesmo, nos erros e acertos de suas decisões e nos efeitos de sua performance. Tal prática discursiva não foi sem consequências. Uma delas foi a ampliação de um quadro sintomático apresentado pelo autor como "depressão nervosa generalizada" (EHRENBERG, 2010, p. 131) e um quadro de toxicomania. A circulação de discursos em torno do uso do medicamento também faz funcionar outra prática discursiva, que naturaliza sua utilização. Para o sociólogo, os medicamentos psicotrópicos superam um uso terapêutico e

[...] são substâncias dopantes para o indivíduo que, na sociedade concorrencial, tem de ir ao fim de si mesmo, como o esportista deve superar seus limites em uma competição. Permitindo construir uma boa imagem ao aparentemente se autocontrolar face ao outro (adversário, concorrente ou parceiro), eles são uma maneira de ser si mesmo que, dependendo do caso, contorna ou reforça o trabalho exercido sobre si. (EHRENBERG, 2010, p. 134-135; negritos nossos)

A partir do fragmento, destacamos que os discursos de mercado, na contemporaneidade, silenciam sentidos em torno do investimento nos afetos. $\mathrm{O}$ sujeito deve contorná-los em seus efeitos e, para erigir sobre si a imagem de sucesso, o uso do medicamento não se faz de maneira controlada e terapêutica, mas torna-se naturalizado 
diante do risco de uma subjetividade que insiste em comparecer. $\mathrm{O}$ autocontrole passa a ser uma demanda do sujeito que, face ao horror do descontrole, lança-se ao uso do medicamento enquanto recurso para tamponar quaisquer sentidos indesejados aos discursos de mercado, sob o risco de produzir sentidos de descontrole, preguiça, fracasso, entre outros efeitos que funcionam enquanto classificações desvalorizadas no universo do trabalho.

Conforme explicam Horwitz \& Wakefield (2010), pessoas que demonstram afetos que se inscrevem em um quadro depressivo (sintoma de tristeza intensa e aguda que não tenha motivos aparentes) são normalmente evitadas e desprezadas por outras pessoas. Bem diferente da "tristeza normal em situações cabíveis" (ibidem, p. 65; negritos nossos), em que há demonstração de apoio por ser uma tristeza cujo motivo está explícito - uma perda, um acidente, entre outras razões.

Em suas reflexões, Pêcheux (2012 [1979]) e Ehrenberg (2010), cada um a seu modo, apontam para determinadas produções de efeitos de evidência, quais sejam: o discurso de mercado ${ }^{3}$ produz sentidos sobre um sujeito empreendedor que pode e deve construir sua história (de sucesso) por conta própria, distanciado de quaisquer sentidos que o relacionem com um passado (a menos que este funcione como comprovação de um sujeito que construiu sua história por conta própria, mobilizado por sua vontade). $\mathrm{O}$ discurso de mercado também constrói sobre o sujeito fortes identificações a partir da área em que atua, silenciando sentidos em torno de questões subjetivas. O sujeito deve sustentar a imagem de um empreendedor que, além disso, tem autocontrole, cuja produção de evidências também se inscreve, conforme nossos gestos de leitura, na materialidade do corpo discursivo.

A necessidade de sustentação da imagem de um sujeito empreendedor e com autocontrole, mas que tem como contraponto uma espécie de horror diante do descompasso que, muitas vezes, se coloca em relação aos afetos, tem por consequência o comparecimento das depressões, cujo controle se faz por meio de medicamentos (antidepressivos, tranquilizantes e ansiolíticos) utilizados de modo indiscriminado, para além do uso controlado. Ehrenberg (2010), detendo-se especialmente na ação dos tranquilizantes (e, acrescentamos, dos ansiolíticos), explica seu funcionamento e os modos pelos quais vêm atendendo a uma demanda de mercado:

os tranquilizantes, [...], não curam as psicoses, não agem sobre a depressão, mas distendem o espírito e dispersam a atenção fixada sobre a angústia. Sua ação age apenas sobre os sintomas: na prática médica cotidiana, são mais medicamentos do conforto psicológico do que instrumentos terapêuticos; são objetos de consumo corrente, na mesma estirpe que a televisão ou o telefone, as vitaminas ou os

\footnotetext{
3 Adotamos a expressão "discurso de mercado" com base no trabalho de Payer (2005). De acordo com a autora, as práticas de subjetivação são construídas por meio de práticas discursivas regulares sustentadas por "textos fundamentais", os quais "guardam e fazem circular os seus 'enunciados-máxima"” (Payer, 2005, p. 15). Payer coloca o "Texto de Mercado" como aquele que marca fortemente a formação social contemporânea e que consiste, de acordo com a autora “[...] da mídia, daquilo que está na mídia, em sentido amplo, e em especial no marketing, na publicidade" (ibidem, p. 16). A autora entende que o poder exercido pela mídia na sociedade é tão relevante a ponto de defender a tese de que a mídia exerce o "[...] papel de Texto fundamental de um novo grande Sujeito, o Mercado, agora em sua forma globalizada" (idem, itálicos do original).
} 
produtos de beleza. Se os psiquiatras os prescrevem, é sobretudo para acompanhar os antidepressivos e evitar seus efeitos negativos no quadro de um protocolo de tratamento. No entanto, a prescrição passa pelos clínicos gerais de acordo com a demanda de seus pacientes. Ela formula-se no quadro de uma dinâmica depressiva de superadaptação. Ao sair da patologia para se inserir na normalidade da vida, os medicamentos psicotrópicos transformamse em técnicas de adaptação a um modo de vida no qual o bem-estar é um estado híbrido que pertence tanto à saúde quanto ao conforto. (EHRENBERG, 2010, p. 151-152; negritos nossos)

O fragmento de Ehrenberg nos permite depreender que, diante dos discursos que circulam sobre trabalho e que produzem sobre o sujeito o peso do imaginário de ser único responsável de sua própria história, o uso de medicamentos não ocorre como uma exigência terapêutica e tampouco passa pelo crivo de profissionais especializados. $\mathrm{O}$ clínico geral torna-se aquele que diante de uma queixa indica o medicamento como um modo do sujeito se adaptar aos discursos de mercado. Ehrenberg (ibidem) situa os medicamentos psicotrópicos enquanto "objetos de consumo" e "técnicas de adaptação", o que produz efeitos de consumo generalizado.

Relacionamos esse consumo generalizado, em nossa formação social, ao termo 'medicalização', que consiste, de acordo com Barros (2004, p. 51), na “crescente e elevada dependência dos indivíduos e da sociedade para com a oferta de serviços e bens de ordem médico-assistencial e seu consumo cada vez mais intensivo".

De uma possibilidade para tratamento terapêutico, os medicamentos são alçados ao conforto de qualquer sujeito - que, conforme compreendemos, passa a ser aquele que na contemporaneidade deve singularizar-se, tornar-se bem sucedido por conta própria. Vale retomar a expressão "sinistro jogo de palavras", de Pêcheux (2012 [1979], p. 88), para fazer luz a um funcionamento discursivo enigmático no qual o sujeito deve se tornar ele mesmo a partir do silenciamento de modelos a serem seguidos e do apagamento sobre o passado de sua história. Uma prática discursiva cujo funcionamento para o sujeito pode ser comparado a uma espécie de rebus que precisa ser decifrado ao mesmo tempo em que é elaborado pelo próprio sujeito.

A relação de forças nos discursos sobre depressão e trabalho comparece também nos processos de textualização no interior das mídias de organismos internacionais, como a Organização Pan-Americana de Saúde. Em artigo para a referida Organização, Wannmacher (2004, on-line) afirma que no decorrer da vida $13 \%$ a $20 \%$ das pessoas apresentam algum episódio depressivo. $\mathrm{O}$ artigo prossegue com o cálculo de quanto isso representa em tempo e em custos para o mercado de trabalho. A autora cita um estudo norte-americano, de 2003, para mostrar quais as despesas do empregador em relação aos casos de depressão. Segundo a autora, a depressão, pela consequente queda na produção, representou naquele ano aos empregadores cerca de $\$ 44$ bilhões de dólares.

É relevante que um artigo disponibilizado pela Organização Pan-Americana da Saúde evidencie uma discursividade voltada à demanda do capital, construindo um imaginário sobre depressão voltado a números ligados ao prejuízo do empregador e à ausência de rendimento de um sujeito que precisa produzir - para o lucro de quem o emprega. 
Este conflito nos discursos sobre trabalho também pode ser compreendido em outras áreas de conhecimento. Nos estudos relacionados à administração de pessoal, Chiavenato (1985, p. 120) explica que o termo 'absenteísmo' expressa a soma dos períodos de ausência do empregado. O autor classifica as principais causas: "doença efetivamente comprovada; doença não comprovada; razões diversas de caráter familiar; atrasos involuntários; e faltas voluntárias por motivos diversos". A depressão, ou um episódio depressivo, pode estar presente em todas as alternativas. O uso do medicamento, nestes casos, atua como um legitimador do quadro depressivo.

Diante da possibilidade de construção de um gesto de resistência do sujeito ao ritual do discurso de mercado, o medicamento e a clínica comparecem como um contraponto, pois a ausência do sujeito no trabalho aponta para um problema ao mesmo tempo em que impele para sua solução. Para Ehrenberg (2010, p. 163-164), o absenteísmo e as falsas doenças eram "meios de se tomar distância com relação às exigências da OST, de zombar a disciplina e a hierarquia". A empresa, segundo o sociólogo, passa a ser a "anticâmara do psicoterapeuta e ou do clínico geral" (ibidem). Um modo de se cristalizar discursos hegemônicos de sentidos sobre a produção no/do trabalho, incluindo a questão da saúde, lugar necessário do bem-estar e cujos discursos de resistência se tornam silenciados a partir desta união entre empresa/indústria e clínica.

Retomando a reflexão sobre os processos de silenciamento (ORLANDI, 2002), é possível compreender que estes ocorrem sobre discursividades voltadas ao questionamento dos processos de reprodução das condições de trabalho, modificadas em decorrência da globalização. Tal processo de silenciamento é produzido em torno das demandas que podem irromper no discurso do e sobre o trabalho, tornando mais agudas as relações de forças, como o aumento da demanda de trabalho, que obriga o sujeito a dedicar uma extensa carga horária para o trabalho pelo risco mesmo de ser demitido. Pode também fazer comparecer um processo discursivo aparentemente menos radical, mas que compromete o sujeito no interior do espaço de trabalho à medida que processos de adjetivação que funcionam enquanto classificações passem a circular sobre o sujeito: preguiçoso, sem vontade, descomprometido.

Cabe pontuar que possuir um trabalho, certamente, não significa o fim dos conflitos subjetivos. Para Bauman (2005), à geração pós 1970 são formuladas e postas em circulação discursividades cujo imaginário valorizado é aquele no qual o jovem aceite todas as demandas do trabalho e seja pouco seletivo com a função que exerce. Para o autor, nesta formulação discursiva está em jogo a construção de uma imagem sobre o trabalho que permite aos jovens "não esperarem demais de seus empregos, aceitá-los como são, sem fazer muitas perguntas, e tratá-los como uma oportunidade a ser usufruída de imediato, enquanto dure, e não como um capítulo introdutório de um "projeto de vida" (BAUMAN, 2005, p. 18).

Neste recorte, Bauman aponta para alguns dos sentidos em jogo nos espaços de trabalho. Entretanto, diante da construção da imagem de um sujeito que tudo deve aceitar, considerando que está trabalhando, recebendo salário e com possibilidades de consumo, algo falha. Diante das práticas discursivas que silenciam discursividades que poderiam instaurar uma mobilização social mais ampla, algo falha e produz um mal-estar individual, que funciona, também, sob a designação "depressão". Deste modo, um possível efeito de sentidos é de que tal investimento em torno de um trabalho, que permita 
consumir e ser classificado como empregado, por exemplo, não é suficiente para aplacar os conflitos subjetivos.

\section{Considerações finais}

Como efeito de encerramento deste percurso, podemos afirmar que nas discursividades contemporâneas em que se coloca como evidente um sujeito que se faz por si mesmo sendo, portanto, autor de sua própria história, o comparecimento de números cada vez mais expressivos em torno da depressão aponta para um sujeito que sucumbe diante de tais produções coercitivas. É relevante considerar que o uso de medicamento ultrapassa o terapêutico, tornando-se cotidiano e generalizado, para dar condições ao sujeito de sustentar a imagem de autocontrole e autor de sua história.

Nossos gestos de leitura, portanto, permitem depreender duas direções de sentidos: de um lado, uma discursividade que produz efeitos de sentidos de depressão como gesto político de resistência; de outro, uma discursividade cujos efeitos permitem inscrever a depressão como gesto político e inconsciente de desistência do sujeito em atender à demanda construída historicamente, sentidos de que algo fracassou nos investimentos diante desta demanda social. Em ambos os efeitos, tanto os de resistência como os de desistência, está em questão a crise subjetiva que rompe com as discursividades hegemônicas. Diferentes modulações para o mesmo sintoma e que apontam para discursos em movimento. Sentidos que coexistem em confronto, em aliança, que mostram um espaço lacunar em torno dos sentidos sobre depressão, apontando que esta pode ser "x" e também " $y$ ", apontando para tensas regiões de sentidos nas quais o quadro depressivo pode se inscrever.

\section{Referências bibliográficas}

BARROS, J.A.C. de. Políticas farmacêuticas: a serviço dos interesses da saúde? Brasília: UNESCO, 2004.

BAUMAN, Z. Vidas desperdiçadas. Trad. Bras. Rio de Janeiro: Jorge Zahar, 2005.

CHIAVENATO, I. Recursos humanos. São Paulo: Atlas, 1985.

EHRENBERG, A. O culto da performance: da aventura empreendedora à depressão nervosa. [Org. e trad. Pedro Bendassoli] Aparecida, SP: Ideias \& Letras, 2010.

FERREIRA, M.C.L. Discurso, arquivo e corpo. Em: MARIANI, B. et al. (Orgs.). Discurso, arquivo e... Rio de Janeiro: 7Letras, 2011. p. 174-183.

HORWITZ, A.V.; WAKEFIELD, J.C. A tristeza perdida: como a psiquiatria transformou a depressão em moda. Trad. Bras. São Paulo: Summus, 2010. 
LUNKES, F.L. O discurso sobre depressão na Revista Veja (1968-2010) em materialidades verbais e não-verbais: o triunfo dos efeitos de sentidos de medicalização. 2014. Tese. Doutorado em Estudos de Linguagem. Instituto de Letras, UFF, Niterói, RJ, 2014.

INDURSKY, F. O texto nos estudos da linguagem: especificidades e limites. Em: ORLANDI, E; LAGAZZY-RODRIGUES, S. (Orgs.). Discurso e textualidade: Introdução às Ciências da Linguagem. 2a . ed. Campinas, SP: Pontes, 2010. p. 33-80.

LAGAZZI, S. O recorte significante da memória. Em: INDURSKY, F. et al (Orgs.). O discurso na contemporaneidade. São Carlos, SP: Claraluz, 2009. p. 65-78.

MARIANI, B.; MAGALHÃES, B. "Eu quero ser feliz": o sujeito, seus desejos e a ideologia. Em: INDURSKY, F. et al (Orgs.). Memória e história na/da análise do discurso. Campinas, SP: Mercado de Letras, 2011. p. 125-141.

MARIANI, B. O PCB e a imprensa: os comunistas no imaginário dos jornais (19221989). Rio de Janeiro: Revan; Campinas, SP: Editora da Unicamp, 1998.

MARX, Karl [1867]. O capital: crítica da economia política. Trad. Bras. São Paulo: Nova cultural, 1996. Volume 1 (O processo de produção do capital).

Terra, 1997.

; ENGELS, F. [1848]. O manifesto comunista. Trad. Bras. Rio de Janeiro: Paz e

NAZAR, J. A medicalização da dor: da psicanálise e da psiquiatria. DIZER, Escola Lacaniana de Psicanálise, Rio de Janeiro, A Escola, semestral, n. 14, p. 95-122, 2003.

ORLANDI, E. O sujeito discursivo contemporâneo: um exemplo. Em: INDURSKY, F; FERREIRA, M.C.L. (Orgs.). Análise do Discurso no Brasil: mapeando conceitos, confrontando limites. São Carlos, SP: Claraluz, 2007. p. 11-20.

As formas do silêncio: no movimento dos sentidos. $5^{\text {a }}$. ed. Campinas, SP: Editora da Unicamp, 2002.

Discurso e texto: formulação e circulação dos sentidos. Campinas: Pontes, 2001.

PAYER, M.O. Linguagem e sociedade contemporânea - sujeito, mídia, mercado. RUA [Revista do Núcleo de Desenvolvimento da criatividade da Unicamp - NUDECRI], Campinas, SP, n. 11, p. 09-25, março 2005.

PÊCHEUX, M. [1979]. Foi "propaganda" mesmo que você disse?. Trad. Bras. Em: ORLANDI, E. (Org.). Análise de Discurso: Michel Pêcheux. $3^{\mathrm{a}}$. ed. Campinas, SP: Pontes, 2012. p.73-92.

[1975]. Semântica e discurso: uma crítica à afirmação do óbvio. $4^{\mathrm{a}}$. ed. Trad.

Bras. Campinas, SP: Editora da Unicamp, 2009. 
[1969]. Análise Automática do Discurso (AAD-69). Em: GADET, F.; HAK, T. Por uma análise automática do discurso: uma introdução à obra de Michel Pêcheux. Trad. Bras. 3ª ed. Campinas, SP: Editora da Unicamp, 1997. p. 61-161.

WANNMACHER, L. Depressão maior: da descoberta à solução? Uso racional de medicamentos: temas selecionados. Brasília, abr. 2004, v. 1, n. 5. Disponível em $<$ http://www.opas.org.br/medicamentos/site/UploadArq/HSE URM DEP 0404.pdf $>$; acesso em ago. 2009.

Artigo recebido em: maio de 2016.

Aprovado e revisado em: junho de 2016.

Publicado em: agosto de 2016

\section{Para citar este texto:}

LUNKES, Fernanda Luzia. O sujeito contemporâneo e o trabalho: um olhar discursivo para os efeitos de medicalização. Entremeios [Revista de Estudos do Discurso], Seção Estudos, Programa de Pós-graduação em Ciências da Linguagem (PPGCL), Universidade do Vale do Sapucaí, Pouso Alegre (MG), vol. 13, p. 111-121, jul. - dez. 2016. DOI: http://dx.doi.org/10.20337/ISSN2179-3514revistaENTREMEIOSvol13pagina111a121 